\title{
TRAIT COMPENSATION IN MARINE GASTROPODS: SHELL SHAPE, AVOIDANCE BEHAVIOR, AND SUSCEPTIBILITY TO PREDATION
}

\author{
Peter A. Cotton, ${ }^{1}$ Simon D. Rundle, and Kathryn E. Smith \\ School of Biological Sciences, University of Plymouth, Plymouth, PL4 8AA, UK
}

\begin{abstract}
Many organisms have evolved morphological and behavioral traits that reduce their susceptibility to predation. However, few studies have explicitly investigated the relationships between defensive traits and susceptibility. Here we demonstrate a negative correlation between morphological defenses and behavioral avoidance across several species of marine gastropod that is linked to vulnerability to crab predation. Snails that had relatively taller shell spires (high aspect ratio) showed greater responsiveness when exposed to predation cues than did species with disc-like shells (low aspect ratio). Our results suggest that the snail species most vulnerable to predation compensated by showing the highest levels of behavioral avoidance, and hence may be at a disadvantage in competition with less vulnerable species. This has important implications because the behavioral response of herbivorous gastropods to predation cues may play a central role in structuring rocky intertidal communities through trait-mediated indirect effects.
\end{abstract}

Key words: avoidance behavior; Carcinus; defensive traits; gastropod; predation; shell morphology; trait compensation; trait mediated indirect effects.

\section{INTRODUCTION}

The evolution of suites of correlated traits is a major theme in studies of morphology and life history (Price and Langen 1992, Zera and Harshman 2001). The joint evolution of anti-predator morphology and behavior has, however, received little attention, despite the fact that predation has selected for diverse morphological, chemical, behavioral, and life-history adaptations in prey organisms (DeWitt et al. 1999). Many prey species show a range of adaptive behavioral responses that reduce their susceptibility to predation, such as reduced activity levels, use of predator-free space, and predator avoidance (Alexander and Covich 1991, Abrahams 1995, Rochette et al. 1999, von Elert and Pohnert 2000). The evolution of such traits that enhance an organism's performance in one activity might be predicted to affect its performance in another, often leading to evolutionary trade-offs (Zera and Harshman 2001). DeWitt et al. (1999) distinguish four functional relationships between traits, including trait compensation, where specialization in one trait is traded off against another. Recent studies have documented trait compensation in defense adaptations within species, but few have demonstrated this relationship across species (Abrahams 1995, Rundle and Brönmark 2001) or provided evidence that the negatively correlated traits are linked to susceptibility to predation.

Interactions between crabs and marine gastropods provide an excellent system to address the relationships between anti-predator behavior and morphology (e.g.,

Manuscript received 21 July 2003; revised 10 December 2003; accepted 15 December 2003. Corresponding Editor: G. E. Forrester.

${ }^{1}$ E-mail: p.cotton@plymouth.ac.uk
Trussell 1997, Trussell and Smith 2000, Trussell and Nicklin 2002). Durophagous crabs have evolved exceptionally strong claws and their long evolutionary history with marine gastropods has led to co-evolved defensive shell structures such as increased thickness, sculpturing, and reduced apical spire (Vermeij 1993). Furthermore, induced responses in shell shape and thickness (Appleton and Palmer 1988, Trussell 1996, Trussell and Smith 2000) have been demonstrated in marine gastropods exposed to the chemical cues of predatory crabs.

Understanding the dynamics of predator-prey interactions between crabs and herbivorous gastropods is of great ecological, as well as evolutionary, significance. The density-mediated indirect effects of predators, such as crabs, are widely recognized as important to the structure of rocky intertidal assemblages because they regulate the density of prey leading to cascading effects on the abundance of primary producers (Menge et al. 1997). Recent experiments have demonstrated that risk cues from shore crabs (Carcinus maenas L.) suppress foraging by Littorina littorea (L.), which, in turn, causes large effects on fucoid algal communities (Trussell et al. 2002). Trait-mediated effects of predators may thus also be an important component of assemblage dynamics in rocky intertidal shores (Trussell et al. 2002).

In this paper, we examined the relationship between shell morphology, shell strength, and behavioral avoidance of four species of marine gastropod that were exposed to predation risk from Carcinus maenas. Our first hypothesis was that morphological and behavioral anti-predator traits would be negatively correlated across species, i.e., that there would be interspecific trait compensation. We also measured Carcinus han-

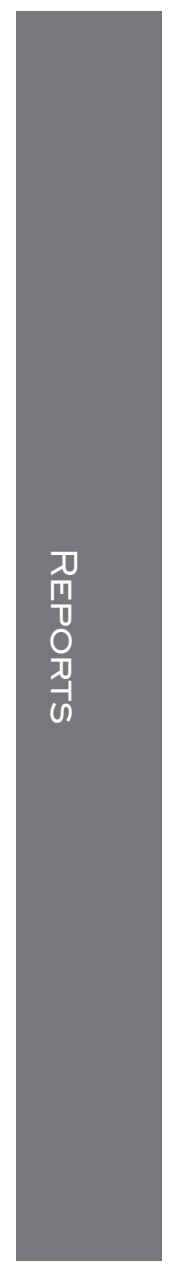


dling times for all gastropod species and assessed whether interspecific differences in resistance to crab predation were related to differences in shell morphology and behavioral avoidance.

\section{Materials And Methods}

\section{Study organisms}

We used four species of intertidal gastropod: grey topshell Gibbula cineraria (L.), flat topshell Gibbula umbilicalis (da Costa), toothed topshell Osilinus lineata (da Costa), and common periwinkle Littorina littorea (L.). All snails were collected between August and October 2002 from Hannafore Point, UK $\left(50^{\circ} 20^{\prime} \mathrm{N}, 4^{\circ} 27^{\prime}\right.$ $\mathrm{W})$. For all experiments, the size of snails used was standardized to a small range $(10.0-11.8 \mathrm{~mm})$. We collected Carcinus in August 2002, from the Plym Estuary, UK $\left(50^{\circ} 22^{\prime} \mathrm{N}, 4^{\circ} 06^{\prime} \mathrm{W}\right)$, and the Yealm Estuary, $\mathrm{UK}\left(50^{\circ} 18^{\prime} \mathrm{N}, 4^{\circ} 03^{\prime} \mathrm{W}\right)$. A total of 28 male crabs were used for the foraging experiments, and a further eight were used to prepare the "predator-cue" water. All crabs were large (average carapace width $=66.1 \mathrm{~mm}$; range $=57.1-78.6 \mathrm{~mm}$ ) and showed no signs of damage or limb loss.

Prior to the experiments, the snails and crabs were maintained in separate aquaria in aerated seawater (35 PSU in the practical salinity scale) at $16^{\circ} \mathrm{C}$ on a natural light cycle. All experiments were conducted under the same conditions. To minimize any effects of prior experience of gastropod species on crab foraging ability, the crabs were maintained on a diet of common mussels (Mytilus edulis L.).

\section{Predator-avoidance behavior}

Gastropod avoidance behavior was assessed using a similar protocol to Rundle and Brönmark (2001). Ten replicate snails of each species were assigned at random to each of two treatments (control or predator-cue), and the position of each treatment and species was randomized between dishes. An individual snail was placed into a circular plastic dish filled to a depth of $4 \mathrm{~cm}$ with seawater (2 L). A "within-habitat" predation refuge was provided by a section of plastic pipe (40 $\mathrm{mm}$ long, $38 \mathrm{~mm}$ diameter). At the start of each trial, a further $200 \mathrm{~mL}$ of control (normal seawater) or predation-cue water was added. Predation-cue water was specific to each gastropod species and was taken from a Plexiglas aquarium containing $5 \mathrm{~L}$ of seawater in which one Carcinus had been maintained for $24 \mathrm{~h}$. Crabs were fed with two snails of the test species at the onset of the maintenance period and a further coarsely crushed snail was added to the tank immediately prior to the trials. This preparation ensured that the snails were exposed to chemical cues from natural predators and crushed conspecifics, a mixture that has been shown to maximize anti-predator behavior (Alexander and Covich 1991, Jacobsen and Stabell 1999).

We recorded the position of the snail immediately after the addition of the treatment water and then at 5- min intervals for $45 \mathrm{~min}$. Because gastropod species differ in their background levels of movement and tendency to crawl out of the water or seek refuge, we used a standardized measure of responsiveness to predator cues (Rundle and Brönmark 2001). Standardized latency was calculated by subtracting the time (minutes) to show avoidance behavior in predator cue trials from the mean background level of movement of that species in control trials.

\section{Shell morphology and resistance to crushing}

We used dial calipers (accuracy $0.05 \mathrm{~mm}$ ) to measure shell width and height. Shell aspect ratio was calculated as height : width. Resistance to crushing is one measure of overall susceptibility to predation (Rundle and Brönmark 2001, Trussell and Nicklin 2002). We measured the compressive force $(\mathrm{kN})$ required to shatter shells using an Instron 4301 Universal testing system (Instron Corporation, Canton, Massachusetts, USA). For each species, we tested 15 individuals with the crushing force applied perpendicular to the axis of coiling. Crushing in this plane provides a representative measure of the resistance to forces exerted on the shell during crab foraging (see Results).

\section{Crab-foraging trials}

Individual crabs were numbered and measured before being randomly assigned to a treatment (gastropod species). There was no significant difference in the maximum carapace size $\left(F_{3,24}=1.363, P>0.05\right)$ or propodus width $\left(F_{3,24}=0.196, P>0.05\right)$ of crabs used for the trials on different gastropod species. Before the trials, each crab was placed in a Plexiglas aquarium filled with $10 \mathrm{~L}$ of seawater and food deprived for 24 h. During the foraging trials, crabs remained in their aquarium and were provided with one live snail, dropped into the tank. Foraging trials were video recorded and later analyzed blind with respect to treatment. We recorded handling time of the crabs, defined as the time in seconds from picking the shell up to the point at which the snail was consumed. Handling time was $\log _{10}$-transformed for analysis.

\section{Statistical analysis}

All statistical analyses were conducted using SPSS 11.5 (SPSS 2003) and all tests were two-tailed. Before conducting ANOVAs, we tested for heterogeneity of variance using Levene's test and transformed variables when significant heterogeneity was detected. Post hoc comparisons were made using Fisher's protected least significant difference test (LSD).

\section{RESULTS}

We found significant differences between marine gastropod species in their standardized latency $\left(F_{3,36}=\right.$ 3.241, $P<0.05$; Fig. 1a). Littorina littorea showed the greatest responsiveness to predator cues, and G. umbilicalis showed the lowest. Post hoc tests showed sig- 

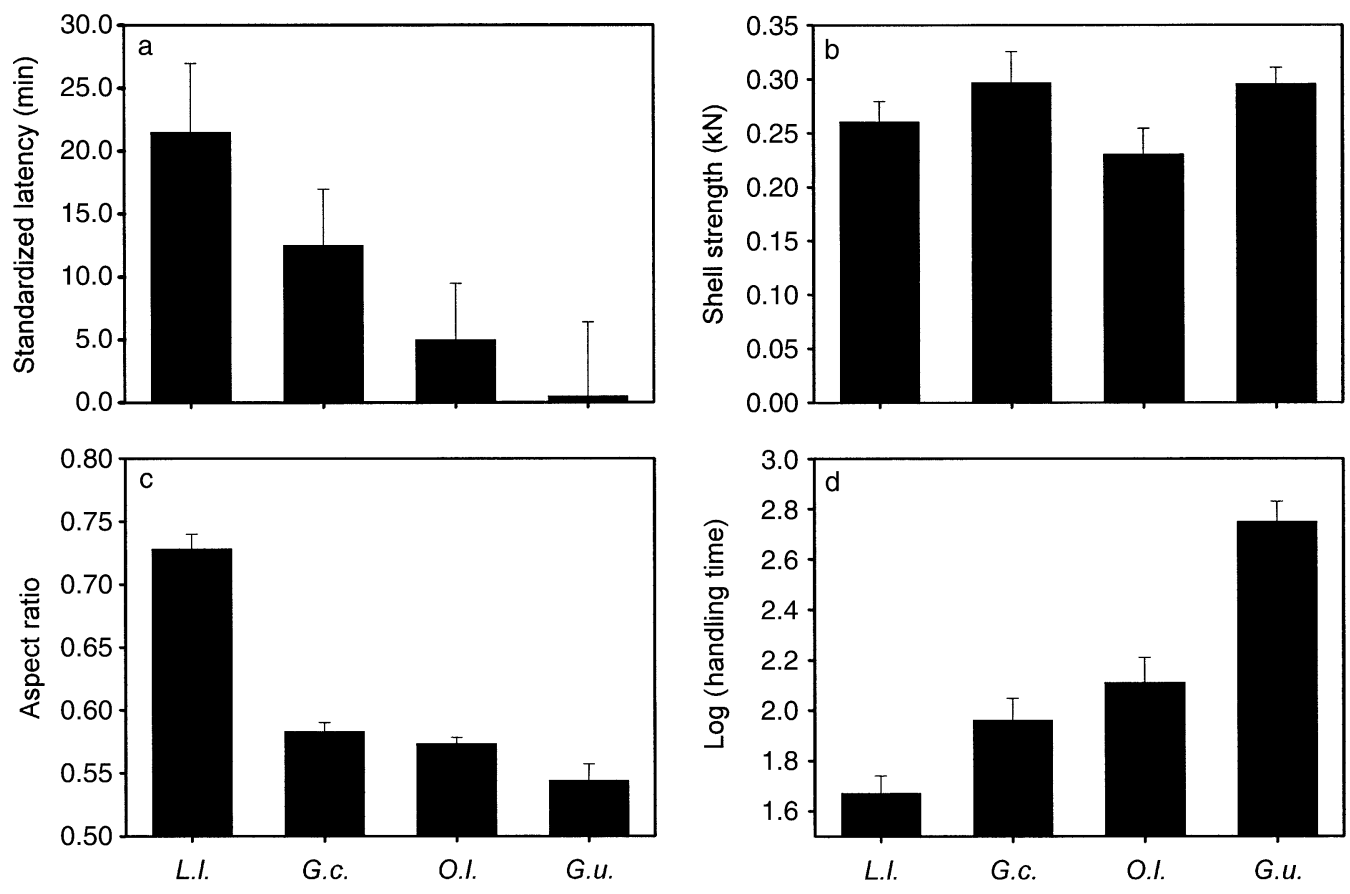

FIG. 1. Interspecific comparisons (mean $+1 \mathrm{sE}$ ) among Littorina littorea (L.l.), Gibbula cineraria (G.c.), Osilinus lineata (O.l.), and Gibbula umbilicalis (G.u.) for: (a) standardized latency to predator avoidance $\left(F_{3.36}=3.241, P<0.05\right.$; post hoc tests, L.l. $=$ G.u. $>$ O.l. $=$ G.u. $)$; (b) shell strength $\left(F_{3,56}=2.071, P>0.05\right)$; (c) shell aspect ratio $\left(F_{3,56}=55.268, P<\right.$ 0.001; post hoc tests, L.l. $>$ G.u. $=$ O.l. $>$ G.u. $)$; and (d) $\log ($ handling time), originally measured in seconds, for Carcinus maenas feeding on live snails $\left(F_{3,24}=29.361, P<0.001\right.$; post hoc tests, L.l. $<$ G.u. $=$ O.l. $<$ G.u. $)$.

nificant pair-wise differences between all species pairs, except $L$. littorea and $G$. cineraria, and $O$. lineata and G. umbilicalis. There were no significant differences between species in shell strength $\left(F_{3,56}=2.071, P>\right.$ 0.05 ; Fig. 1b), but we found highly significant species differences for shell aspect ratio $\left(F_{3,56}=55.268, P<\right.$ 0.001 ; Fig. 1c). Gibbula umbilicalis had the flattest, most disc-like shells (low aspect ratio), and L. littorea had the tallest spires (high aspect ratio). All pair-wise post hoc tests were significant, except between $G$. cineraria and $O$. lineata.

In all trials, the crabs crushed the spire of the shells in a transverse plane, and then ate the snail. To do this, the crabs manipulated the shell such that the apex was held in their mandibles while the minor claw held the shell across the aperture. The crabs then used their major claw to crush the shell posterior to the last whorl. Most of the handling time was spent in manipulating the shell into a suitable position for force to be applied. Once the shell was in position, it seldom took more than a few attempts to crush the shell. We found significant species differences in log handling time $\left(F_{3,24}\right.$ $=29.361, P<0.001$; Fig. $1 \mathrm{~d}) ;$ L littorea shells took the least time for crabs to break, and G. umbilicalis shells the longest time. All post hoc tests were significant, except between $G$. cineraria and $O$. lineata.

\section{DISCUSSION}

Our results provide evidence for an interspecific trait compensation of behavioral and morphological anti- predator defenses in marine gastropods that is linked to susceptibility to crab predation. Gastropod species (e.g., G. umbilicalis) with flat, disc-like shells took longer for crabs to handle and consume than did those with shells with taller spires (e.g., L. littorea), but snails with pointed shells showed greater responsiveness to predation cues. From a general perspective, these results support those of Rundle and Brönmark (2001), which demonstrated interspecific trait compensation in anti-predator adaptations in freshwater gastropods. An important difference between these two studies is that, unlike Rundle and Brönmark (2001), we found no evidence that shell strength was related to predator resistance or behavioral avoidance. This was surprising, given the evidence that shell strength is an important determinant of susceptibility to predation (West et al. 1991, Lowell et al. 1994, Brown 1998). Clearly shell strength will be related to vulnerability, but it appears that once predator size and shell size are controlled for, the residual effect of shell shape on predation resistance becomes apparent.

Our findings have important implications for the ecology and evolution of marine gastropods. The recent demonstration of trait mediated indirect effects in littoral food webs (Trussell et al. 2003) suggests that the behavioral response of gastropod prey to predation cues may play an important role in structuring rocky intertidal communities. From our findings, we predict that competitive interactions between intertidal gastropods 
may be related to their susceptibility to predation. Specifically, those species that are less vulnerable to predation would be expected to show less behavioral avoidance and refuge use, and hence be at a competitive advantage. It is likely that trait compensations are the result of diffuse selection by predators across relatively large time scales. Recent invasions by predatory crabs have been shown to lead to plastic responses in intertidal gastropods in the form of increased shell strength. It remains to be seen how such plasticity might influence intra- and interspecific trade-offs between antipredator behavior and morphology.

\section{ACKNOWLEDGMENTS}

We thank Jo Vosper for technical support, Terry Richards for assistance with the Instrom testing system, and John Spicer, Graham Forrester, and two anonymous referees for comments on the manuscript. This research was supported by grant NER/B/5/2001/00843 from the Natural Environment Research Council, UK.

\section{Literature Cited}

Abrahams, M. V. 1995. The interaction between antipredator behaviour and antipredator morphology: experiments with fathead minnows and brook sticklebacks. Canadian Journal of Zoology 73:2209-2215.

Alexander, J. E., and A. P. Covich. 1991. Predator avoidance by the freshwater snail Physella virgata in response to the crayfish Procambarus simulans. Oecologia 87:435-442.

Appleton, R. D., and A. R. Palmer. 1988. Water-borne stimuli released by predatory crabs and damaged prey induce more predator-resistant shells in a marine gastropod. Proceedings of the National Academy of Sciences USA 85:4387-4391.

Brown, K. M. 1998. The role of shell strength in selective foraging by crayfish for gastropod prey. Freshwater Biology 40:255-260.

DeWitt, T. J., A. Sih, and J. A. Hucko. 1999. Trait compensation and cospecialization in a freshwater snail: size, shape and antipredator behaviour. Animal Behaviour 58:397407.

Jacobsen, H. P., and O. B. Stabell. 1999. Predator-induced alarm responses in the common periwinkle, Littorina littorea: dependence on season, light conditions, and chemical labelling of predators. Marine Biology 134:551-557.

Lowell, R. B., C. R. Fletcher, J. Grahame, and P. J. Mill. 1994. Ontogeny of shell morphology and shell strength of the marine snails Littorina obtusata and Littorina mariae: different defense strategies in a pair of sympatric, sibling species. Journal of Zoology 234:149-164.

Menge, B. A., B. A. Daley, P. A. Wheeler, E. Dahlhoff, E. Sanford, and P. T. Strub. 1997. Benthic-pelagic links and rocky intertidal communities: bottom-up effects on topdown control? Proceedings of the National Academy of Sciences USA 94:14530-14535.

Price, T., and T. Langen. 1992. Evolution of correlated characters. Trends in Ecology and Evolution 7:307-310.

Rochette, R., M. J. Maltais, L. M. Dill, and J. H. Himmelman. 1999. Interpopulation and context-related differences in responses of a marine gastropod to predation risk. Animal Behaviour 57:977-987.

Rundle, S. D., and C. Brönmark. 2001. Inter- and intraspecific trait compensation of defence mechanisms in freshwater snails. Proceedings of the Royal Society of London, Series B 268: 1463-1468.

SPSS. 2003. SPSS for Windows. Version 11.5. SPSS, Chicago, Illinois, USA.

Trussell, G. C. 1996. Phenotypic plasticity in an intertidal snail: the role of a common crab predator. Evolution 50: 448-454.

Trussell, G. C. 1997. Phenotypic plasticity in the foot size of an intertidal snail. Ecology 78:1033-1048.

Trussell, G. C., P. J. Ewanchuk, and M. D. Bertness. 2002. Field evidence of trait-mediated indirect interactions in a rocky intertidal food web. Ecology Letters 5:241-245.

Trussell, G. C., P. J. Ewanchuk, and M. D. Bertness. 2003. Trait-mediated effects in rocky intertidal food chains: predator risk cues alter prey feeding rates. Ecology 84:629640.

Trussell, G. C., and M. O. Nicklin. 2002. Cue sensitivity, inducible defense, and trade-offs in a marine snail. Ecology 83:1635-1647.

Trussell, G. C., and L. D. Smith. 2000. Induced defenses in response to an invading crab predator: an explanation of historical and geographic phenotypic change. Proceedings of the National Academy of Sciences USA 97:2123-2127.

Vermeij, G. J. 1993. A natural history of shells. Princeton University Press, Princeton, New Jersey, USA.

von Elert, E., and G. Pohnert. 2000. Predator specificity of kairomones in diel vertical migration of Daphnia: a chemical approach. Oikos 88:119-128.

West, K., A. Cohen, and M. Baron. 1991. Morphology and behavior of crabs and gastropods from Lake Tanganyika, Africa-implications for lacustrine predator-prey coevolution. Evolution 45:589-607.

Zera, A. J., and L. G. Harshman. 2001. The physiology of life history trade-offs in animals. Annual Review of Ecology and Systematics 32:95-126. 